\title{
0095. Transvenous vagus nerve stimulation does not modulate the innate immune response in humans in vivo during experimental endotoxemia
}

\author{
M Kox ${ }^{1,2^{*}}$, LT van Eijk ${ }^{1,2}$, T Frenzel $^{1,2}$, T Verhaak $^{1,2}, J F$ Gerretsen ${ }^{1,2}, J G$ van der Hoeven ${ }^{1,2}$, L Kornet $^{3}$, A Scheiner $^{4}$, \\ P Pickkers ${ }^{1,2}$
}

From ESICM LIVES 2014

Barcelona, Spain. 27 September - 1 October 2014

\section{Introduction}

In a variety of conditions excessive and/or persistent activation of the innate immune system has detrimental effects. In animals, electrical vagus nerve stimulation (VNS) inhibits the innate immune response in models of endotoxemia (administration of lipopolysaccharide [LPS]), sepsis, trauma, and hemorrhagic shock, via the so-called cholinergic anti-inflammatory pathway. However, human in vivo evidence is lacking. Up till now, VNS was possible through implantation of a cuff electrode wrapped around the nerve, which limits its use in acute inflammatory situations frequently encountered on the ICU. A novel, less invasive VNS method is transvenous VNS (tVNS).

\section{Objective}

To determine whether tVNS exerts anti-inflammatory effects during experimental human endotoxemia.

\section{Methods}

A parallel randomized double-blind sham-controlled study in healthy male volunteers was performed. Subjects were randomized to receive either tVNS $(n=10)$ or sham tVNS $(\mathrm{n}=10)$.

In both groups, a stimulation catheter with multiple circular electrode pairs was inserted in the left internal jugular vein at $\mathrm{C} 5-\mathrm{C} 7$ spinal level to be situated adjacent to the vagal nerve. In the tVNS group, stimulation $(0-10 \mathrm{~V}, 1 \mathrm{~ms}, 20 \mathrm{~Hz})$ was continuously performed during 30 minutes, starting 10 minutes before intravenous administration of $2 \mathrm{ng} / \mathrm{kg}$ E. Coli LPS. In sham subjects, the exact same procedures were performed, but the stimulator was not switched on by an unblinded team member.

\section{Results}

In all 20 subjects placement of the stimulation electrode was successful and uneventful. Furthermore, in all subjects of the tVNS group, laryngeal vibration was confirmed by an unblinded team member, indicating stimulation of vagal fibers. LPS administration resulted in an increase in heart rate of $26 \pm 3 \mathrm{bpm}$ and a decrease in mean arterial pressure of $16 \pm 2 \mathrm{mmHg}$, as well as fever (increase of $1.5 \pm 0.1{ }^{\circ} \mathrm{C}$ ) and flu-like symptoms. No differences between groups were observed. Furthermore, plasma levels of inflammatory cytokines increased sharply, but responses were similar between groups (Figure 1). Likewise, cytokine production by leukocytes ex vivo restimulated with LPS as well as neutrophil phagocytosis capacity were unaffected by tVNS. Finally, heart rate variability analysis revealed that during (sham) stimulation, the ratio between low frequency and high frequency (HF) spectral power was significantly lower, and HF power in normalized units significantly higher in the tVNS group compared with the sham group, suggestive of increased parasympathethic activity (Figure 2, $\mathrm{p}=0.02$ for both indices, unpaired Student's t-test at $\mathrm{T}=0$ ). However, when corrected for baseline differences, this effect was no longer statistically significant ( $p=0.35$ for both indices). 

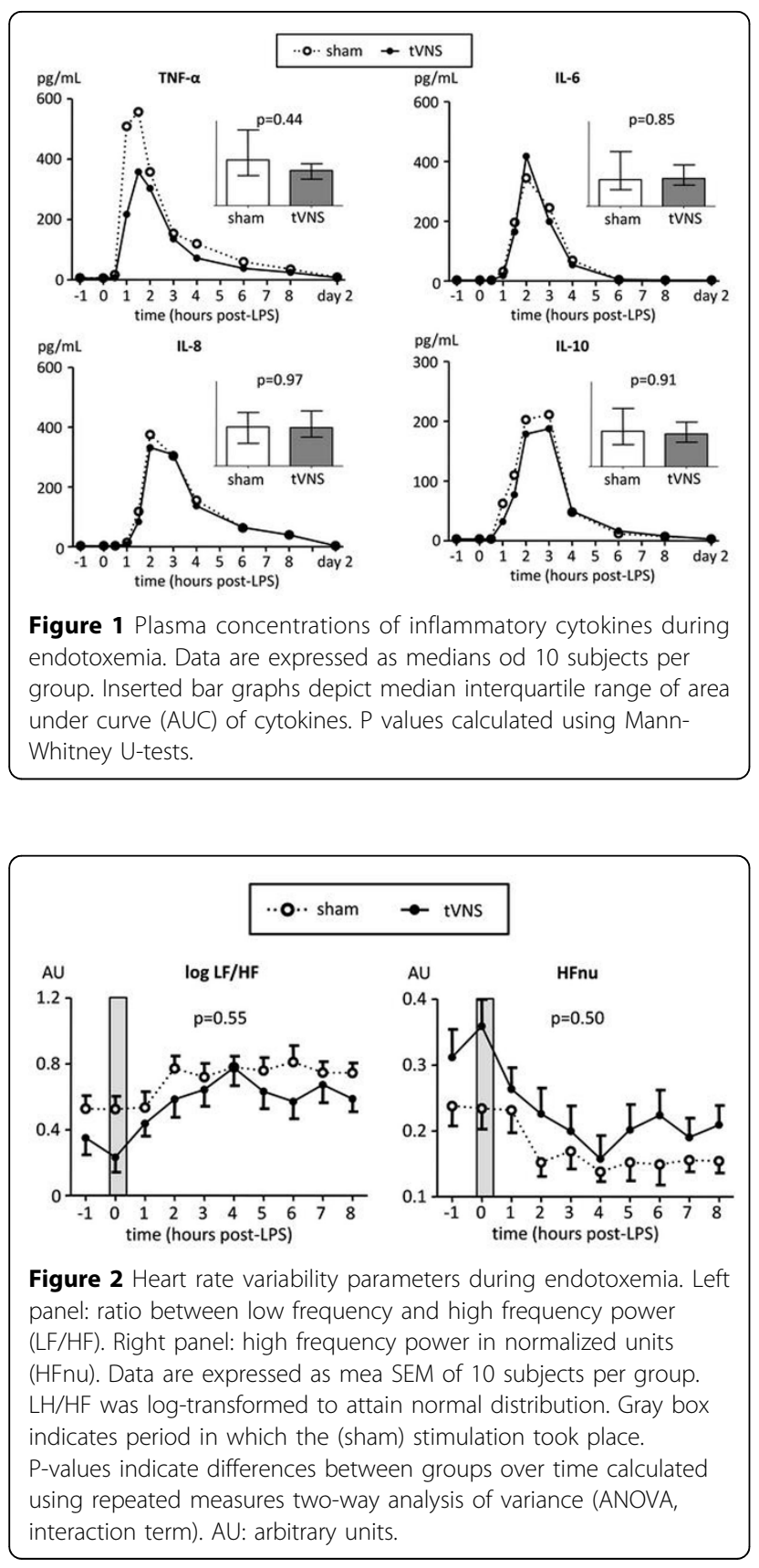

\section{Conclusions}

Thirty-minute transvenous vagus nerve stimulation is feasible and safe but does not modulate the innate immune response in humans in vivo during experimental human endotoxemia.

\section{Grant acknowledgment}

This study was sponsored by Medtronic Inc.

\section{Authors' details}

${ }^{1}$ Radboud University Medical Center, Intensive Care Medicine, Nijmegen, Netherlands. 'Radboud Institute for Infectious Diseases, Nijmegen,
Netherlands. ${ }^{3}$ Medtronic Inc., Maastricht, Netherlands. ${ }^{4}$ Medtronic Inc., St. Paul, MN, USA.

Published: 26 September 2014

doi:10.1186/2197-425X-2-S1-P7

Cite this article as: Kox et al:: 0095. Transvenous vagus nerve stimulation does not modulate the innate immune response in humans in vivo during experimental endotoxemia. Intensive Care Medicine Experimental 2014 2(Suppl 1):P7.

\section{Submit your manuscript to a SpringerOpen ${ }^{\circ}$ journal and benefit from:}

- Convenient online submission

- Rigorous peer review

- Immediate publication on acceptance

- Open access: articles freely available online

- High visibility within the field

- Retaining the copyright to your article

Submit your next manuscript at $\boldsymbol{~ s p r i n g e r o p e n . c o m ~}$ 